\title{
Relationship of the Magnitude of Member Cost-Share and Medication Persistence With Newly Initiated Renin Angiotensin System Blockers
}

\author{
Dongmu Zhang, PhD; Angeline M. Carlson, PhD; Patrick P. Gleason, PharmD; \\ Stephen W. Schondelmeyer, PhD; Jon C. Schommer, PhD; Bryan E. Dowd, PhD; \\ and Alan H. Heaton, PharmD
}

\begin{abstract}
BACKGROUND: Effective treatment for chronic diseases often requires medication refill persistence. Health plans have frequently increased the amount of member cost-sharing by implementing tier-copayment pharmacy benefit designs and raising copayments. However, increased member costshare may present a barrier to the management of chronic conditions. Little is known about the relationship between the magnitude of member cost-sharing and antihypertensive persistence among members newly initiating therapy.
\end{abstract}

OBJECTIVE: To investigate and quantify the relationship between amount of prescription cost-sharing and medication refill persistence among members newly initiating therapy with a single-agent angiotensin system blockereither an angiotensin-converting enzyme inhibitor (ACEI) or angiotensin II receptor blocker (ARB).

METHODS: This was an observational cohort study of pharmacy and medical claims data for 29 employers with approximately 310,000 beneficiaries that did not have a change in pharmacy benefits including the amount of member cost-share in 2004. The claims data were supplemented with census data for household income and race at the Zip Code level. Selected patients were new users of single-agent ACEIs or ARBs (i.e., excluding ACEI or ARB in combination with hydrochlorothiazide or amlopdipine) between January 1 and June 30,2004 , without a pharmacy claim for an ACEl or an ARB in the 6 months prior to the index claim for either drug type. Medication refill persistence was measured in 3 ways: (1) total number of days without ACEls or ARBs during 6 months follow-up, (2) proportion of days covered (PDC) with less than $80 \%$ defined as nonpersistent during 6 months follow-up, and (3) number of days to the first gap of more than 30 days in medication coverage from the index date to end of 2004 (mean [SD] follow-up=9.2 [1.8] months). Three statistical models were fit: Tobit model, examining the association between cost-sharing and total number of medication gap days; logistic regression, testing the association between cost-sharing and odds of being nonpersistent; and Cox proportional hazards model, assessing the association between cost-sharing and time to a 30-day gap.

RESULTS: Among the eligible population, a study cohort of 1,351 members newly initiating a single-agent ACEI or ARB was identified. These members were $41.8 \%$ female and had a mean age of $55.9(S D=13.1)$ years. On average, their member cost-share was $\$ 12.42(\mathrm{SD}=\$ 8.50)$ per 30-day supply. Each $\$ 1$ increment in per 30-day cost-share was associated with a $1.9 \%$ increase in total gap ( $\beta=0.019,95 \%$ confidence interval [Cl], 0.007-0.030, $P=0.001)$, a $2.8 \%$ increase in the odds of being nonpersistent (odds ratio $[\mathrm{OR}]=1.028,95 \%$ $\mathrm{Cl}, 1.011-1.045, P=0.001)$, and a $1.0 \%$ increase in the risk of having a gap of more than 30 days (hazard ratio [HR] $=1.010,95 \% \mathrm{Cl}, 1.001-1.019, P=0.034$ ). Following transformation of the cost-sharing coefficient in each model, a $\$ 10$ increment in cost-share had a consistent negative influence; $18.9 \%$ greater total gap days $(\beta=0.189,95 \% \mathrm{Cl}, 0.073-0.304), 31.9 \%$ greater odds of being nonpersistent ( $\mathrm{OR}=1.319,95 \% \mathrm{Cl}, 1.120-1.553)$, and $10.2 \%$ larger hazard of having a gap of more than 30 days $(\mathrm{HR}=1.102,95 \% \mathrm{Cl}, 1.007-1.205)$.

CONCLUSION: For members newly initiating single-agent angiotensin system blocking medication, the amount of prescription cost-sharing was associated with a negative impact on refill persistence.
Keywords: ACEl inhibitors, ARBs, Cost-sharing, Hypertension, Persistence

J Manag Care Pharm. 2007;13(8):664-676

Copyright@ 2007 , Academy of Managed Care Pharmacy. All rights reserved.

\section{What is already known about this subject}

- In a quasi-experimental (pre-post with comparison group) study, rates of persistency with antihypertensive therapy were not significantly affected by the implementation of a cost-share increase of $\$ 13$ per prescription for $29 \%$ of antihypertensive use and $\$ 1$ to $\$ 3$ for the remaining $71 \%$ of antihypertensive use.

- When comparing antihypertensive persistence among 3 benefit tiers (generics, preferred brands, and nonpreferred brands), using the measure of proportion of days covered, researchers have found an inverse association between costshare and persistence.

- The quantitative relationship between antihypertensive costsharing and persistence among members newly initiating therapy is unknown.

\section{What this study adds}

- Among members newly initiating angiotensin system blocking medication, each $\$ 1$ increment in member cost-share for the initial prescription claim was associated with $2.8 \%$ greater odds of being nonpersistent at 6 months after initiating therapy.

- Among members newly initiating angiotensin system blocking medication, each $\$ 1$ in member cost-share for the initial prescription claim was associated with a $1.9 \%$ increase in total medication gap in therapy.

- The magnitude of member cost-share was found to have a consistent effect on medication persistence by 3 measures: total gap, odds of being nonpersistent, and risk for a 30 day gap.

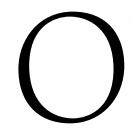
utpatient prescription drug spending in the United States was $\$ 200.7$ billion in 2005 with a $5.8 \%$ increase over 2004. ${ }^{1}$ To control rising prescription drug costs, managed care organizations (MCOs) and the employers with whom they contract began utilizing multitiered formularies after the early 1990s. ${ }^{2}$ To offset the continued increase in prescription drug spending, many health plans have increased prescription cost-sharing across all copayment tiers. ${ }^{2}$ In 2006, the most common commercial pharmacy benefit design employed 3-tier copayments with average member cost-share of $\$ 11$ for 
generic drugs, $\$ 24$ for preferred brand-name drugs, and $\$ 38$ for nonpreferred brand-name drugs. ${ }^{3}$

One rationale behind prescription cost-sharing is to make consumers sensitive to prescription costs so that they will limit "nonessential" use and utilize generic or less expensive branded drugs when needed. In a recent literature summary of 65 studies, researchers examined prescription drug cost-sharing associations with medication and medical utilization and spending. ${ }^{4}$ Using an unspecified meta-analytic calculation methodology, the authors found that for each $10 \%$ increase in cost-sharing, prescription drug spending decreased by $2 \%$ to $6 \%$, dependent upon the drug class and the patient conditions. In a statistical model derived from a cross-sectional analysis of claims data from 25 employers, it was estimated that doubling a member's copayment was associated with a 22\% to $35 \%$ reduction in average annual prescription drug spending per member, with a proportional reduction in utilization. ${ }^{5}$ Other well-designed studies assessing pharmaceutical utilization and spending associated with changes to the pharmacy benefit design, as defined by Goldman et al., demonstrated similar trends in decreased utilization and costs associated with increased cost-share. ${ }^{6-23}$ However, in several of the better designed (e.g., pre-post with comparison group) studies evaluating the effect of benefit design changes, which result in higher cost-share to some members, researchers found much smaller decreases in utilization than observed in the cross-sectional studies. These authors also found significant shifts from nonpreferred products to preferred products, one of the desired outcomes of multitier pharmacy benefit designs. ${ }^{14-15,20-22} \mathrm{~A}$ pre-post comparison of utilization of diabetes medication suggested that a greater than $\$ 10$ increase in cost-share is necessary to induce a significant decrease in utilization. ${ }^{11}$

An unintended consequence of large increases in cost-sharing with subsequent large reductions in prescription drug spending may be that members forgo "essential" medication use, raising concern about adverse health outcomes, particularly for individuals with chronic illness. ${ }^{9}$ In a well-designed pre-post with comparison group study, the authors found no significant differences in medical utilization, including inpatient hospital admissions, emergency room visits, and office visits, following implementation of a copayment increase..$^{21-22}$ That study also found that rates of persistency with antihypertensive and antilipidemic therapy were not significantly affected by the copayment change. The minimal association between medical outcomes and pharmacy cost-share in that study may in part be due to the small increases in cost-sharing most members experienced; cost-sharing went from a 2-tier structure of $\$ 7$ and $\$ 12$ to a 3-tier of $\$ 8, \$ 15$, and $\$ 25$. Based on pre-implementation claims, only $14 \%$ of overall utilization, $29 \%$ of antihypertensive utilization, and $11 \%$ of antilipidemic utilization were subject to the largest increase in cost-share from $\$ 12$ to $\$ 25$. All other members' cost-sharing went from either $\$ 7$ to $\$ 8$ or from $\$ 12$ to $\$ 15$.
In addition, an assessment of a Canadian provincial health system change in prescription coverage from $\$ 2$ copayment per prescription to $25 \%$ coinsurance with income-based out-ofpocket annual maximums showed no dramatic differences in persistence or in cardiovascular outcomes in a pre-post design. ${ }^{24}$ This Canadian study is limited because it is not possible to quantify the individual difference in cost-share per prescription, and the U.S. health system lacks a comparable type of benefit design with income-based annual out-of-pocket maximum cost-share.

It is important to develop an understanding of the incremental effect that member cost-sharing has on "essential" medication persistence, especially for members newly initiating medication therapy. Among cardiovascular medications shown to reduce medical events, such as antihypertensives and lipid-lowering therapy, a handful of researchers have examined the association between prescription cost-sharing and medication persistence, but without consistent results. . $^{6-9,14,17,20,23-27}$ These studies have consisted of a mix of users newly initiating and those currently on therapy. Another limitation of these studies is inconsistency in the definition of persistence and persistence measurement methodology. ${ }^{28}$ Therefore, it is difficult to make comparisons between studies.

Persistence is generally measured in 3 ways, as a function of: (1) medication possession ratio (MPR) or proportion of days covered (PDC); (2) medication availability at a fixed time point; or (3) gaps in medication coverage..$^{29}$ Even though quasi-experimental study design (pre-post with comparison group) has good internal validity, it can only examine whether there is an impact of prescription cost-sharing on persistence based on the magnitude of cost-sharing change. The fixed cost-sharing in pre-post comparison studies does not allow assessment of a continuous quantitative relationship between cost-share and persistence. Furthermore, in pre-post comparison studies, not only the effects of prescription cost-sharing, but also the responses toward a pharmacy benefits change, are measured. In most cross-sectional studies, cost-sharing is either assessed by a price index or approximated by formulary tiers, neither of which measures members' actual economic burden. To our knowledge, at the time of this research, no one had investigated members newly initiated on therapy and the associated proportional effect of prescription cost-sharing on the level of nonpersistence. Finally, the main purpose of most of the published studies was to quantify the impact of a change in cost-sharing on prescription drug utilization, expenditure, and persistence. . $^{8-9,14,17,20,24}$

To our knowledge, the studies of cardiovascular drugs in which authors have attempted to quantify mathematically the relationship between cost-share and persistence were in the statin drug class $6,7,25$ or focused on congestive heart failure patients. ${ }^{23}$ Two antihypertensive studies evaluating the relationship between persistence and member cost-share focused on differences in persistence between 3 copayment tiers using the PDC metric. ${ }^{26,27}$ Both of the antihypertensive studies found that 
higher cost-share was a significant independent negative predictor of persistence. However, the studies are limited due to the use of 1 persistence measure and the inability to quantify the relationship between the amount of cost-share and persistence.

The objective in this study was to investigate and quantify the influence of the amount of prescription cost-share on medication refill persistence among members newly initiating angiotensin system-blockers: angiotensin converting enzyme inhibitors (ACEIs) or angiotensin II receptor blockers (ARBs). ACEIs and ARBs are primarily prescribed for hypertension ${ }^{30}$ and have been associated with higher persistence rates than other antihypertensive therapeutic classes. ${ }^{31-33}$ They have a similar mechanism of action, reducing the effect of angiotensin II on the body, and nearly identical side effect profiles with a higher proportion of patients reporting cough with ACEIs. ${ }^{34-35}$ The equivalent effectiveness and safety of ACEIs and ARBs has been recently reported in the Agency for Health Research and Quality document "Comparative effectiveness of angiotensin-converting enzyme inhibitors (ACEIs) and angiotensin II receptor antagonists (ARBs) for treating hypertension." ${ }^{35}$

During the present study, 6 single-agent ACEIs were available by generic name (captopril, enalapril, fosinopril, lisinopril, moexipril, and benazepril), 4 single-agent ACEIs were available as brand only (trandolapril, perindopril, quinapril, and ramipril), and all single-agent ARBs were available as brand only. This distribution of study drugs across copayment tiers permits analysis of the relationship between cost-share amount and persistence.

\section{METHODS}

This observational cohort study used a Midwest commercial insurer's medical and pharmacy administrative claims data for health benefit services provided to 1.7 million members. To be eligible for analysis, members were required to have been continuously enrolled from July 1, 2003 to December 31, 2004 with a health plan group, pharmacy benefit, and cost-share that did not change during 2004. There were 29 employers that met these criteria, representing approximately $10 \%$ of the total membership of this commercial insurer. From these 29 employers, we identified new users of single angiotensin systemblocking (ACEI or ARB) agents. Combination products were excluded because the single angiotensin system-blocking agents are associated with significantly higher persistence rates than other antihypertensive drug classes. ${ }^{36}$ By limiting the analysis to single-agent angiotensin system blockers, we reduce the potential for agents such as hydrochlorothiazide in combination products to negatively influence persistence. A new user was defined as an individual who started treatment with ACEI (Medi-Span's 6-digit Generic Product Identifier [GPI] code 361000) or ARB (code 361500) single agents (excluding ACEI/ calcium channel blockers, ACEI/hydrochlorothiazide, and ARB/ hydrochlorothiazide combinations) between January 1, 2004 and June 30, 2004 with no ACEI or ARB single agents or combinations dispensed in the 6 months (180 days) preceding the index date.

The first pharmacy claim for an ACEI or ARB single agent was defined as the index event, and the date of the index pharmacy claim was defined as the index date. The new users had to meet several inclusion criteria: (1) 18 years of age or older on the index date, (2) at least 28 days supply in the index pharmacy claim, (3) no facility hospitalization or long-term care claim of any duration after the index date, and (4) no diagnosis of dementia (ICD-9-CM codes 290.xx, 294.1x, 331.0x, 331.1x or 331.2x). Members were followed for 2 periods: from the index date to 6 months after the index date and from the index date to the end of 2004.

\section{Variables}

Medication refill persistence was measured 3 ways based on days supply recorded in pharmacy claims to quantify the intensity and duration:28,29 (1) total gap or total number of days without medication during the first 6 months of treatment, (2) proportion of days covered (PDC) with less than $80 \%$ defined as nonpersistent (less than 144 days of coverage) during the first 6 months of treatment, and (3) time to a gap of more than 30 days in medication coverage from the index date to the end of 2004. Days supply that overlapped with previous pharmacy claims or extended past the observation period were not used in calculating persistence. Switching to a single-agent ARB or ACEI was counted as a continuation of treatment as long as the other criteria for continuation (e.g., no more than a 30-day gap) were met. However, members switching to a combination product or to an antihypertensive product in a different therapy class (e.g., beta blockers, calcium channel blockers) were defined as having terminated therapy on the date that the switch claim was filled. Members' out-of-pocket payment for the index prescription as recorded in pharmacy claims was used to measure cost-sharing after adjusting to a 30 days supply (cost-sharing for the initial claim was divided by days supply to yield cost-sharing per day, then multiplied by 30).

Control variables were selected according to Andersen's behavioral model of health services use ${ }^{37}$ and previous empirical studies. ${ }^{6-7,23,25,31-33,36,38-41}$ Andersen's model was originally developed in the late 1960s to explain how and why families use health services. This model has since been adapted to predict and explain prescription drug use. ${ }^{42-44}$ According to the model, use of health services, including prescription drugs, is a function of patients' predisposing characteristics, enabling resources, and need factors. In this study, predisposing characteristics are those variables that describe the predisposition of individuals to continuously use an angiotensin system blocker; enabling resources describe the ability of patients to continuously obtain and use an angiotensin system blocker; and need factors describe the professionally determined requirements for continuous use of 
an angiotensin system blocker.

Predisposing characteristics included age, gender, race, and whether a member previously used any antihypertensive medications other than ACEIs and ARBs. Because race is not available in claims data, it was controlled on an aggregate level using percentage of people who reported their race as white only in a member's Zip Code area based on the Census 2000 data. ${ }^{45}$ Other antihypertensives included diuretics (General Product Indentifier Code beginning 37), beta-blockers (33), calcium channel blockers (34), antiadrenergic antihypertensives (3620), aldosterone receptor blockers (3625), direct vasodilators (364000), and antihypertensive combinations (3699) without ACEIs and ARBs.

Enabling resources included residence (urban, rural, or super rural); income; number of unique medications in prior 6 months; number of doctor visits from July 1, 2003 to the end of 2004; initial therapeutic class (ACEIs or ARBs); utilization of mail-order service at any time during follow-up; presence of a yearly out-of-pocket maximum in member's pharmacy benefits; and whether a member used any antidepressant medications: mirtazapine (GPI code 580300), trazodone (58120080), monoamine oxidase inhibitors (581000), selective serotonin reuptake inhibitors (SSRIs, 581600), serotonin norepinephrine reuptake inhibitors (SNRIs, 581800), tricyclic agents (582000), and miscellaneous antidepressants (583000) in the prior 6 months. Tricyclic agents were not coded as antidepressant medications in those members with a diagnosis of diabetes as these drugs are often used for diabetic neuropathy.

Zip Codes were used to classify members as living in an urban, rural, or super rural area according to the Medicare ambulance fee schedule of the Center for Medicare and Medicaid Services (CMS). ${ }^{46}$ A rural area is defined as an area outside a Metropolitan Statistical Area (MSA) or a New England County Metropolitan Area, or an area within an MSA identified as rural using the Goldsmith modification. ${ }^{47} \mathrm{~A}$ super rural area is defined as a rural area determined by the Secretary of Housing and Urban Development to be in the lowest 25th percentile of all rural population arrayed by population density. ${ }^{48}$ An area that is not classified as a rural or super rural area is considered an urban area. Income was also controlled on an aggregate level using household median income in a member's Zip Code area based on the Census 2000 Data. ${ }^{45}$

Need factors controlled for included conditions that angiotensin system blocking medications are generally used to treat or conditions associated with treatment. These conditions were based on the International Classification of Diseases, Ninth Revision, Clinical Modification (ICD-9-CM) diagnosis and procedure codes recorded in medical claims between July 1, 2003 and December 31, 2004. Diagnoses included essential hypertension (ICD9-CM 401.xx), myocardial infarction (410.xx, 411.0x, 412. xx, 414.8x, 429.7x), congestive heart failure (398.91, 402.01, $402.11,402.91,404.01,404.03,404.11,404.13$, 404.91,
404.93, 425.4x, 428.xx), cerebrovascular diseases (362.34, 430.xx-438.xx, 784.3x, 997.02, 38.12 (P), 38.42(P), diabetes (250.xx), and dyslipidemia (272.xx).

\section{Statistical Analysis}

Statistical analyses were conducted using SAS 9.1 (SAS Institute Inc., Cary, NC). Results were considered statistically significant at $P<0.05$ (2-tailed). Descriptive statistics, numbers, and percentages for categorical variables and means and standard deviations for continuous variables were calculated. These descriptive results were also stratified by cost-sharing tertiles. Cost-sharing tertiles were constructed according to the frequency distribution of cost-sharing, with each containing about one third of the study members. Comparisons of control variables across cost-sharing tertiles were conducted with chi-square tests for categorical variables and analyses of variance (ANOVA) for continuous variables. Three statistical models corresponding to the 3 measures of medication refill persistence were performed: Tobit model (proc lifereg), logistic regression (proc logistic) and Cox proportional hazards model (proc phreg). All of these models adjusted for the same set of control variables.

The Tobit model was used to model the association between cost-sharing and total gap over the first 6 months of treatment. This approach is appropriate for a dependent variable with a distribution that is spread out over a large range of positive values but with a large proportion of observations at the value zero. In this study, total gap has such a distribution. Although a linear model could capture the expected value of such a dependent variable, a linear model will likely lead to negative predictions for some subjects. In the Tobit model, a natural logarithmic transformation of total gap is used to address the skewness in the distribution of total gap. Because the natural logarithm of zero is not defined, every patient's total gap is added by one. Normal distribution after log transformation is a critical assumption under the Tobit model. This assumption was examined using histogram of residuals (i.e., predicted total gap minus actual total gap). In this study, the histogram of residuals shows that the normal distribution assumption under the Tobit model is met (data not shown).

Logistic regression, which is appropriate for describing the relationship between a categorical dependent variable and a set of predictors, was used to examine the association between cost-sharing and being nonpersistent (PDC $<80 \%$ ) during the first 6 months of treatment. The overall fit of the logistic model was assessed using the Hosmer-Lemeshow test. This test divides subjects into deciles based on predicted probabilities, then computes a chi-square from observed and expected frequencies. When the test is not significant ( $P$ value $\geq 0.05$ ), the null hypothesis that the model fits the data well cannot be rejected. The logistic regression model in this study has a Hosmer-Lemeshow goodness-of-fit test $P$ value of 0.10 suggesting that the 
model fits the data $\left(\chi^{2}[8]=13.27\right)$.

Cox proportional hazards model with the Breslow method for ties was used to test the association between cost-sharing and time to a gap of more than 30 days from the index date to the end of 2004. The Cox proportional hazards model assesses the effects of different covariates on logarithm of rate (log[rate]), without assuming a constant rate over time. A crucial assumption of the Cox proportional hazards model is proportional hazards (i.e., the hazard of having an event at any given time for an individual in one group is proportional to the hazard at that time for a similar individual in the other group.) This assumption was examined by plotting the log-cumulative hazard functions against the $\log (t)$. For this study, the plot of $\log$-cumulative hazard functions against the $\log (t)$ suggests that the proportional hazards assumption was satisfied (data not shown). Survival curves stratified by cost-sharing tertiles were shown after adjusting for all the control variables in the Cox proportional hazards model.

\section{Patient Privacy}

A limited data set was received after direct individual identifiers were removed to meet the requirements of the Health Insurance Portability and Accountability Act (HIPAA). Year of birth and Zip Codes are allowed in limited data sets. This study was approved by the University of Minnesota's Institutional Review Board.

\section{RESULTS}

There were 175,374 members who were continuously enrolled from July 1, 2003 to December 31, 2004 with a health plan group, pharmacy benefit, and cost-share that did not change during 2004. A total of 1,610 new users of an angiotensin system-blocking single agent were found between January 1 , 2004 and June 30, 2004. Two hundred and fifty-seven members were excluded due to the inclusion criteria (see Figure 1). Two additional members were excluded because they filled both an ACEI and an ARB single agent on the same index date. The final study cohort included 1,351 members.

Table 1 shows the members' pharmacy benefits designs. A majority of the members had a multitier formulary with $52.9 \%$ in a 2-tier copayment structure and $42.6 \%$ in a 3-tier structure. The use of a coinsurance-only pharmacy-benefits design was rare $(0.4 \%$ of members) in this study cohort.

As shown in Table 2, the cohort was $41.8 \%$ female, with a mean age of $55.9(S D=13.1)$ years (range $=18-97)$. On average, study members initially paid $\$ 12.42(\mathrm{SD}=\$ 8.50)$ for a 30 days supply of an angiotensin system-blocking agent. Extrapolations from the Zip Code census data indicate that the study members lived in relatively wealthy areas (mean of household median incomes for the Zip Code $=\$ 46,366[S D=\$ 14,449]$ ) with the majority of residents being white (mean percentage of white people in the Zip Code $=89.4 \%$ [SD $=13.2 \%]$ ). Characteristics of the study members were comparable across cost-sharing tertiles
FIGURE 1 Algorithm to Select the Sample of Angiotensin-Converting Enzyme Inhibitor (ACEI) or Angiotensin II Receptor Blocker (ARB) New Users

Membership file: $\mathrm{n}=1.7$ million

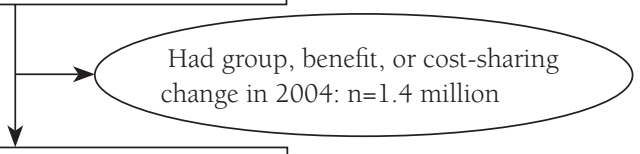

No group, benefit, or cost-sharing changes in 2004: $n=309,604$

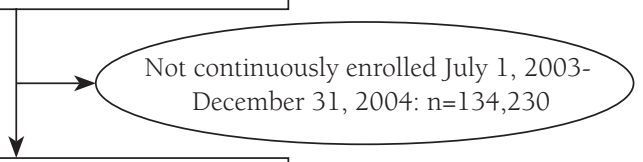

Continuous enrollment July 1, 2003-

December 31, 2004: $n=175,374$

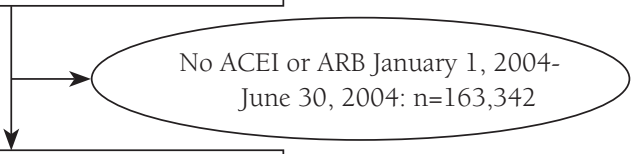

At least 1 ACEI or ARB claim January 1, 2004June 30, 2004: $\mathrm{n}=12,032$

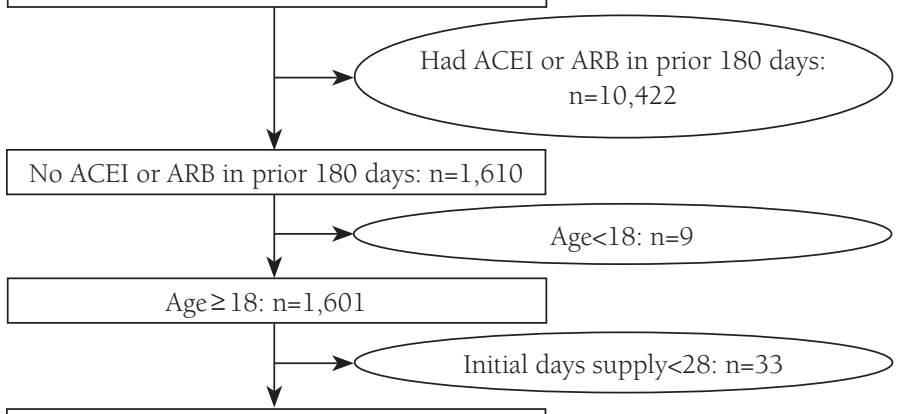

Initial days supply $\geq 28: \mathrm{n}=1,568$

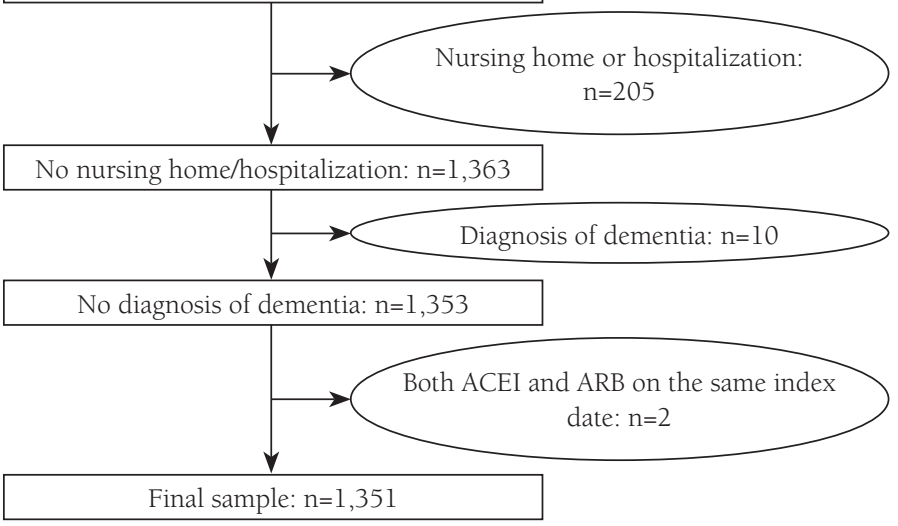


Relationship of the Magnitude of Member Cost-Share and

Medication Persistence with Newly Initiated Renin Angiotensin System Blockers

(TABLE 1$)$ Pharmacy Benefits Design ( $N=1,351)$

\begin{tabular}{|c|c|c|}
\hline Benefits Design & Members (n) & $\%$ \\
\hline \multicolumn{3}{|l|}{ Mandatory generic substitution ${ }^{*}$} \\
\hline Yes & 1,082 & 80.1 \\
\hline No & 269 & 19.9 \\
\hline \multicolumn{3}{|l|}{ Formulary tiers ${ }^{\dagger}$} \\
\hline 1 copayment tier & 62 & 4.6 \\
\hline 2 copayment tiers & 714 & 52.9 \\
\hline 3 copayment tiers & 575 & 42.6 \\
\hline \multicolumn{3}{|l|}{ Type of cost-sharing ${ }^{\ddagger}$} \\
\hline Coinsurance only & 6 & 0.4 \\
\hline Copayment only & 1,011 & 74.8 \\
\hline Copayment and Coinsurance & 334 & 24.7 \\
\hline \multicolumn{3}{|l|}{ Pharmacy deductible§ } \\
\hline Yes & 113 & 8.4 \\
\hline No & 1,238 & 91.6 \\
\hline \multicolumn{3}{|l|}{ Yearly out-of-pocket maximum" } \\
\hline Yes & 613 & 45.4 \\
\hline No & 738 & 54.6 \\
\hline \multicolumn{3}{|c|}{ Per-prescription out-of-pocket maximum 9} \\
\hline Yes & 62 & 4.6 \\
\hline No & 1,289 & 95.4 \\
\hline
\end{tabular}

* Mandatory generic substitution is defined as the member's benefit requires the member receive a generic when a generic identical chemical entity is available.

† The most common copayment single-tier was $\$ 15$ ( $\$ 30$ for 90 days for mail order), 2-tier was $\$ 15 / \$ 30$ ( $\$ 30 / \$ 60$ for mail order), and 3-tier was $\$ 10 / \$ 20 / \$ 30$ ( $\$ 20 / \$ 40 / \$ 60$ for mail order).

\# The most common coinsurance rate was $20 \%$.

$\S$ The most common pharmacy deductible was $\$ 100$ per member per year

II The most common yearly out-of-pocket maximum was $\$ 1,500$ per member or $\$ 2,500$ per family

II The most common out-of-pocket maximum per prescription was $\$ 40$ (\$120 for mail order)

(Table 2). Members who paid the highest cost-sharing amount for their initial claim were more likely to start with ARBs than members who paid lower cost-sharing amounts. This is expected because all ARBs were brand drugs and had higher cost-share than ACEIs, which were mostly available as generics. In addition, members who were in the third cost-sharing tertile (highest cost-sharing amount) lived in a Zip Code with lower household median income, had fewer doctor visits, and were less likely to have a yearly out-of-pocket maximum in their pharmacy benefits design compared with the members in the other 2 tertiles. The second cost-sharing tertile had significantly fewer members who used mail-order pharmacies and more members who had a diagnosis of essential hypertension compared with the first and third tertiles. These differences were adjusted in our multivariate analyses.

During the first 6 months of treatment, the study members, on average, had $53(\mathrm{SD}=52)$ days (range $=0-152$ ) without an angiotensin system blocking agent. During the first 6 months, $8 \%$ of these members had no gap and $47 \%$ were classified as being nonpersistent (PDC $<80 \%$ ). From the index date to the end of 2004,54\% of these members had a gap of more than 30 days with an average time to the gap of $172(S D=108)$ days.

\section{Results of the Tobit Model}

Table 3 shows the results from the Tobit model. After controlling for members' other characteristics, the coefficient of costsharing was 0.019 (95\% confidence interval [CI], 0.007-0.030, $P=0.001$ ). Interpreting the coefficients in a Tobit model can be challenging because the marginal impact of $X$ on $Y$ is nonlinear. The approach is to take the Tobit estimate and multiply it by a factor to obtain the marginal impact. The factor is the standard normal cumulative distribution function at the sample mean values of all the independent variables, which in our case was 0.98 (almost 1). Therefore, the Tobit model suggests that starting at the mean values of all the independent variables including cost-sharing, a $\$ 1$ increase in cost-sharing was associated with an approximate $1.9 \%$ increase in total gap. Following transformation of the cost-sharing coefficient, a $\$ 10$ greater cost-share was associated with an approximate $18.9 \%$ increase in total gap (95\% CI, 7.3\%-30.4\%).

Besides cost-sharing, 6 other significant independent predictors were identified. A 1-year increase in age was associated with an approximate $1.2 \%$ decrease in total gap. Residing in Zip Code areas with a higher prevalence of white residents, using mail-order service, having an out-of-pocket annual maximum on prescription drug spending, and having diagnoses of dyslipidemia and myocardial infarction were also associated with a lower total gap. Specifically, a 1\% increase in the proportion of white people in the member's Zip Code was associated with a $1.1 \%$ decrease in total gap; members who used mailorder service had a $86.4 \%$ lower total gap than those who did not use mail-order service; members who had an out-of-pocket annual maximum on prescription drug spending had a 29.7\% lower total gap than those who did not have this benefit; and members who were diagnosed with dyslipidemia and myocardial infarction had a $20.5 \%$ and $47.5 \%$ lower total gap compared with those who did not have these diagnoses, respectively.

\section{Results of Logistic Regression}

Table 4 shows the results from the logistic regression model. After adjusting for the control variables, a $\$ 1$ increase in costsharing was associated with a $2.8 \%$ increase in the odds of being nonpersistent (odds ratio $[\mathrm{OR}]=1.028,95 \% \mathrm{CI}, 1.011$ $1.045, P=0.001$ ). Following transformation of the cost-sharing coefficient, a $\$ 10$ increase in cost-sharing was associated with a 
Relationship of the Magnitude of Member Cost-Share and Medication Persistence with Newly Initiated Renin Angiotensin System Blockers

TABLE 2 Characteristics of Study Members ( $N=1,351)$

\begin{tabular}{|c|c|c|c|c|c|}
\hline Variables & Copay Tertile 1 & Copay Tertile 2 & Copay Tertile3 & Total & $P$ Value* \\
\hline & $\begin{array}{l}\$ 0.00-\$ 8.30 \\
\mathrm{n}=452\end{array}$ & $\begin{array}{c}\$ 8.31-\$ 13.00 \\
n=455\end{array}$ & $\begin{array}{c}\$ 13.01-\$ 127.98 \\
n=444\end{array}$ & $\begin{array}{c}\$ 0.00-\$ 127.98 \\
\mathrm{n}=1,351\end{array}$ & \\
\hline Mean initial cost-sharing per 30 days supply [SD] & $6.29[1.93]$ & $9.45[0.88]$ & $21.71[9.03]$ & $12.42[8.50]$ & $<0.001$ \\
\hline \multicolumn{6}{|l|}{ Predisposing characteristics } \\
\hline Mean age in years [SD] & $56.0[12.7]$ & $56.6[12.8]$ & $55.1[13.7]$ & $55.9[13.1]$ & 0.247 \\
\hline Female (\%) & 39.8 & 43.5 & 42.1 & 41.8 & 0.523 \\
\hline Other antihypertensives previously (\%) & 43.4 & 42.4 & 43.2 & 57.0 & 0.952 \\
\hline Mean \% of white people in Zip Code [SD] & 89.8 [13.2] & $89.8[12.4]$ & $88.5[13.9]$ & $89.4[13.2]$ & 0.212 \\
\hline \multicolumn{6}{|l|}{ Enabling resources } \\
\hline Residence (\%) & & & & & 0.584 \\
\hline Urban & 64.8 & 60.7 & 61.5 & 62.3 & \\
\hline Rural & 20.4 & 24.2 & 24.3 & 23.0 & \\
\hline Super Rural $\dagger$ & 14.8 & 15.2 & 14.2 & 14.7 & \\
\hline $\begin{array}{l}\text { Mean of the median income values for patients' Zip Codes } \\
\text { [SD] }\end{array}$ & $\begin{array}{c}47,642 \\
{[14,480]}\end{array}$ & $\begin{array}{c}46,526 \\
{[14,015]}\end{array}$ & $\begin{array}{c}44,902 \\
{[14,751]}\end{array}$ & $\begin{array}{c}46,366 \\
{[14,449]}\end{array}$ & 0.017 \\
\hline Mean number of unique medications in prior 6 months [SD] & $3.9[3.5]$ & $3.7[3.3]$ & $4.2[3.6]$ & $3.9[3.5]$ & 0.088 \\
\hline Initiated with ACEIs (\%) & 96.9 & 92.5 & 44.6 & 78.2 & $<0.001$ \\
\hline Mail-order service in 6 months follow-up (\%) & 16.2 & 12.3 & 18.2 & 15.5 & 0.045 \\
\hline Mean number of doctor visits July 1, 2003-December 31, 2004 [SD] & $6.4[7.8]$ & $5.9[7.5]$ & $4.7[7.3]$ & $5.7[7.6]$ & 0.003 \\
\hline Depression $(\%) \ddagger$ & 15.7 & 15.0 & 15.5 & 15.4 & 0.946 \\
\hline Yearly out-of-pocket maximum (\%) & 53.8 & 47.9 & 34.2 & 45.4 & $<0.001$ \\
\hline \multicolumn{6}{|l|}{ Need factors $\S$} \\
\hline Essential hypertension & 73.2 & 83.3 & 74.3 & 77.0 & $<0.001$ \\
\hline Myocardial infarction & 7.3 & 4.4 & 5.9 & 5.9 & 0.176 \\
\hline Congestive heart failure & 8.4 & 6.2 & 5.9 & 6.8 & 0.251 \\
\hline Diabetes & 31.4 & 25.7 & 28.4 & 28.5 & 0.164 \\
\hline Dyslipidemia & 50.7 & 49.9 & 53.4 & 51.3 & 0.548 \\
\hline Cerebrovascular disease & 5.1 & 4.0 & 6.8 & 5.3 & 0.167 \\
\hline \multicolumn{6}{|l|}{ Days supply } \\
\hline Mean total days supply in 6 months follow-up [SD] & $164.7[71.9]$ & $143.0[71.3]$ & $142.4[72.7]$ & $150.1[72.7]$ & $<0.001$ \\
\hline Mean total mail-order days supply in 6 months follow-up [SD]" & $186.7[78.3]$ & $164.8[71.3]$ & $168.1[69.1]$ & $173.7[73.3]$ & 0.166 \\
\hline
\end{tabular}

* The statistical tests used to derive these P values were chi-square test for categorical variables and analysis of variance (ANOVA) for continuous variables.

$\dagger$ Super rural is defined as a rural area determined by the Secretary of Housing and Urban Development to be in the lowest 25th percentile of all rural populations arrayed by population density. ${ }^{49}$

\# Depression was identified by looking at whether a member used any antidepressant medications: mirtazapine (GPI code 580300), trazodone (58120080),

monoamine oxidase inhibitors (581000), selective serotonin reuptake inhibitors (SSRIs, 581600), serotonin-norepinephrine reuptake inhibitors (SNRIs, 581800),

tricyclic agents (582000), and miscellaneous antidepressants (583000) in the prior 6 months.

$\S$ Medical conditions in the "need factors" were identified using ICD-9-CM (the International Classification of Diseases-Ninth Revision-Clinical Modification) diagnosis and procedure codes recorded in medical claims between July 1, 2003 and December 31, 2004. Essential hypertension (ICD-9-CM 401.xx), myocardial infarction (410.xx, 411.0x, 412.xx, 414.8x, 429.7x), congestive heart failure (398.91, 402.01, 402.11, 402.91, 404.01, 404.03, 404.11, 404.13, 404.91, 404.93, $425.4 x, 428 . x x)$, cerebrovascular diseases (362.34, 430.xx-438.xx, 784.3x, 997.02, $38.12(P), 38.42(P)$, diabetes (250.xx), and dyslipidemia (272.xx).

"Mean mail-order days supply in 6 months follow-up is derived from those members who used mail-order service during the 6 months follow-up.

ACEI=angiotensin converting enzyme inhibitor 


\section{TABLE 3 Results of the Tobit Model to Assess Association Between Cost-Sharing and Total Gap (N=1,351)}

\begin{tabular}{|c|c|c|c|c|}
\hline \multirow{2}{*}{$\begin{array}{l}\text { Variables } \\
\text { Initial cost-sharing } \\
\text { per } 30 \text { days supply }\end{array}$} & \multirow{2}{*}{$\frac{\text { Coefficient }}{0.019^{*}}$} & \multicolumn{2}{|c|}{$95 \% \mathrm{CI}$} & \multirow{2}{*}{$\frac{P \text { Value }}{0.001}$} \\
\hline & & 0.007 & 0.030 & \\
\hline \multicolumn{5}{|l|}{ Predisposing characteristics } \\
\hline Age & $-0.012 *$ & -0.019 & -0.005 & 0.002 \\
\hline Female & 0.111 & -0.065 & 0.286 & 0.216 \\
\hline $\begin{array}{l}\text { Pre-use of } \\
\text { antihypertensives }\end{array}$ & 0.100 & -0.098 & 0.298 & 0.322 \\
\hline $\begin{array}{l}\% \text { of population self- } \\
\text { reporting white race only }\end{array}$ & $-0.011^{*}$ & -0.018 & -0.004 & 0.001 \\
\hline \multicolumn{5}{|l|}{ Enabling resources } \\
\hline Living in rural area & 0.153 & -0.083 & 0.388 & 0.204 \\
\hline $\begin{array}{l}\text { Living in super } \\
\text { rural area }{ }^{\dagger}\end{array}$ & 0.076 & -0.209 & 0.361 & 0.602 \\
\hline $\begin{array}{l}\text { Household median } \\
\text { income (thousands) }\end{array}$ & 0.001 & -0.007 & 0.008 & 0.888 \\
\hline Treatment for depression & 0.093 & -0.167 & 0.353 & 0.484 \\
\hline Initiated with ACEIs & -0.017 & -0.253 & 0.220 & 0.891 \\
\hline $\begin{array}{l}\text { Unique medications } \\
\text { in prior } 6 \text { months (n) }\end{array}$ & -0.021 & -0.054 & 0.012 & 0.206 \\
\hline Mail-order service & $-0.864 *$ & -1.121 & -0.608 & $<0.001$ \\
\hline $\begin{array}{l}\text { Doctor visits July 1, 2003- } \\
\text { December 31, } 2004 \text { (n) }\end{array}$ & 0.000 & -0.013 & 0.014 & 0.953 \\
\hline $\begin{array}{l}\text { Yearly out of pocket } \\
\text { maximum }\end{array}$ & $-0.297^{*}$ & -0.489 & -0.105 & 0.003 \\
\hline
\end{tabular}

\begin{tabular}{l|c|c|c|c}
\hline \multicolumn{4}{l|}{ Need factors } \\
\hline $\begin{array}{l}\text { Diagnosis of myocardial } \\
\text { infarction }\end{array}$ & $-0.475^{*}$ & -0.853 & -0.097 & 0.014 \\
\hline $\begin{array}{l}\text { Diagnosis of congestive } \\
\text { heart failure }\end{array}$ & 0.088 & -0.265 & 0.440 & 0.626 \\
\hline $\begin{array}{l}\text { Diagnosis of } \\
\text { cerebrovascular disease }\end{array}$ & 0.397 & 0.005 & 0.789 & 0.050 \\
\hline $\begin{array}{l}\text { Diagnosis of essential } \\
\text { hypertension }\end{array}$ & 0.002 & -0.206 & 0.209 & 0.986 \\
\hline $\begin{array}{l}\text { Diagnosis of diabetes } \\
\begin{array}{l}\text { Diagnosis of } \\
\text { dyslipidemia }\end{array}\end{array}-0.077$ & $-0.205 *$ & -0.382 & -0.029 & 0.023 \\
\hline Constant & $4.884 *$ & 4.055 & 5.713 & $<0.001$ \\
\hline
\end{tabular}

* Denotes statistically significant comparison, $P<0.05$.

$L R x^{2}(20)=147.35, P$ value $<0.001, A C E I=$ angiotensin-converting enzyme inhibitor + Super rural is defined as a rural area determined by the Secretary of Housing and

Urban Development to be in the lowest 25 th percentile of all rural populations arrayed by population density. 49
$31.9 \%$ increase in the odds of being nonpersistent $(\mathrm{OR}=1.319$, 95\% CI, 1.120-1.553).

In addition to cost-sharing, 3 control variables were also significant in predicting the odds of being nonpersistent. A 1 -year increase in age was associated with a $2.0 \%$ decrease in the odds of being nonpersistent. A $1 \%$ increase in the proportion of Caucasians in the member's Zip Code was associated with a 1.4\% decrease in the odds of being nonpersistent. Members who used mail-order service had a $43.0 \%$ lower odds of being nonpersistent compared to those who did not use mail-order service.

\section{Results of the Cox Proportional Hazards Model}

Table 5 presents the results of the Cox proportional hazards model with the Breslow method for ties. Each \$1 in cost share per 30-day supply was associated with a $1.0 \%$ greater risk of having a gap of more than 30 days in the coverage of ACEI or ARB single agents (hazard ratio $[\mathrm{HR}]=1.010,95 \% \mathrm{CI}, 1.001$ $1.019, P=0.034$ ). Following transformation of the cost-sharing coefficient, a $\$ 10$ increase in cost-share per 30-day supply was associated with a $10.2 \%$ increase in the risk of having a gap of more than 30 days (HR=1.102, 95\% CI, 1.007-1.205).

Consistent with the Tobit model and logistic regression, age, residing in Zip Code census areas with a higher prevalence of white residents, and using mail-order service were also significant predictors of the risk of having a gap of more than 30 days in the coverage of ACEIs or ARBs. A 1-year increase in age was associated with a $1.1 \%$ decrease in the risk of having a gap of more than 30 days. A $1 \%$ increase in the proportion of white residents in the member's Zip Code was associated with a $0.8 \%$ decrease in the risk of having a 30 day gap. Members who used mail-order service had a $22.0 \%$ lower risk of having a gap of greater than 30 days than those who did not use mail-order service.

Figure 2 shows the estimated survival curves after adjusting for all control variables at the mean values in the Cox proportional hazards model. The survival curves were stratified by cost-sharing tertiles. The survivor function decreases over time and more dramatically in the higher cost-sharing tertile. After up to 1 year of follow-up, 10\% more members in the lowest cost-sharing tertile $(\$ 0.00-\$ 8.30)$ were still persistent (i.e., not having a 30 day gap yet) compared with those in the highest cost-sharing tertile (\$13.01-\$127.98).

\section{DISCUSSION}

Angiotensin system-blocking medication refill persistence intensity and duration among members newly initiating therapy were consistently found to be independently associated with cost-share. In addition, the relationship between medication persistence and cost-share, quantified as $\$ 1$ greater cost-share, was associated with a $1.9 \%$ larger medication gap during the first 6 months of treatment. To our knowledge, these findings are the first to quantify the relationship between 


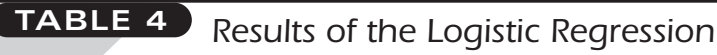

to Assess Association Between

Cost-Sharing and Odds of Being Nonpersistent $(\mathrm{N}=1,351)$

\begin{tabular}{|c|c|c|c|c|}
\hline \multirow{2}{*}{$\begin{array}{l}\text { Variables } \\
\text { Initial cost-sharing per } \\
30 \text { days supply }\end{array}$} & \multirow{2}{*}{$\begin{array}{c}\text { Odds } \\
\text { Ratio } \\
1.028^{*}\end{array}$} & \multicolumn{2}{|c|}{$95 \%$ CI } & \multirow{2}{*}{$\frac{P \text { Value }}{0.001}$} \\
\hline & & 1.011 & 1.045 & \\
\hline \multicolumn{5}{|l|}{ Predisposing characteristics } \\
\hline Age & $0.980^{*}$ & 0.970 & 0.989 & $<0.001$ \\
\hline Female & 1.125 & 0.892 & 1.418 & 0.320 \\
\hline Pre-use of antihypertensives & 1.187 & 0.915 & 1.540 & 0.197 \\
\hline $\begin{array}{l}\% \text { of population self-reporting } \\
\text { white race only }\end{array}$ & $0.986^{*}$ & 0.976 & 0.995 & 0.003 \\
\hline \multicolumn{5}{|l|}{ Enabling resources } \\
\hline Living in rural area & 1.358 & 0.996 & 1.852 & 0.053 \\
\hline Living in super rural area $\dagger$ & 1.172 & 0.806 & 1.703 & 0.407 \\
\hline $\begin{array}{l}\text { Household median income } \\
\text { (thousands) }\end{array}$ & 1.001 & 0.991 & 1.010 & 0.906 \\
\hline Treatment for depression & 0.871 & 0.618 & 1.227 & 0.429 \\
\hline Initiated with ACEIs & 0.947 & 0.690 & 1.299 & 0.735 \\
\hline $\begin{array}{l}\text { Unique medications } \\
\text { in prior } 6 \text { months (n) }\end{array}$ & 0.997 & 0.955 & 1.041 & 0.884 \\
\hline Mail-order service & $0.570^{*}$ & 0.404 & 0.804 & 0.001 \\
\hline $\begin{array}{l}\text { Doctor visits July 1, 2003- } \\
\text { December 31, } 2004 \text { (n) }\end{array}$ & 0.999 & 0.981 & 1.017 & 0.904 \\
\hline Yearly out of pocket maximum & 0.907 & 0.704 & 1.168 & 0.449 \\
\hline \multicolumn{5}{|l|}{ Need factors } \\
\hline $\begin{array}{l}\text { Diagnosis of myocardial } \\
\text { infarction }\end{array}$ & 0.745 & 0.449 & 1.238 & 0.256 \\
\hline $\begin{array}{l}\text { Diagnosis of congestive } \\
\text { heart failure }\end{array}$ & 0.993 & 0.619 & 1.593 & 0.975 \\
\hline $\begin{array}{l}\text { Diagnosis of cerebrovascular } \\
\text { disease }\end{array}$ & 1.471 & 0.872 & 2.479 & 0.148 \\
\hline $\begin{array}{l}\text { Diagnosis of essential } \\
\text { hypertension }\end{array}$ & 0.996 & 0.757 & 1.310 & 0.976 \\
\hline Diagnosis of diabetes & 0.971 & 0.746 & 1.264 & 0.827 \\
\hline Diagnosis of dyslipidemia & 0.843 & 0.668 & 1.064 & 0.150 \\
\hline
\end{tabular}

* Denotes statistically signifrant comparison, $P<0.05$.

$L R x^{2}(20)=97.82, P$ value $<0.001, A C E I=$ angiotensin-converting enzyme inhibitor . + Super rural is defined as a rural area determined by the Secretary of Housing and Urban Development to be in the lowest 25 th percentile of all rural populations arrayed by population density. ${ }^{49}$

persistence and the amount of member cost-share for patients newly initiating angiotensin system-blocking medication.

Previously published studies focusing on pharmacy benefit design cost-sharing changes have shown minimal impact on antihypertensive persistence among current utilizers. These
TABLE 5 Results of the Cox Proportional Hazards Model to Assess Association Between Cost-Sharing and Risk to Have a Gap of More Than 30 Days $(\mathrm{N}=1,351)$

\begin{tabular}{l|c|c|c|c}
\hline & $\begin{array}{c}\text { Hazard } \\
\text { Ratio }\end{array}$ & \multicolumn{2}{|c|}{$95 \%$ CI } & P Value \\
\hline $\begin{array}{l}\text { Initial cost-sharing per } \\
\text { 30 days supply }\end{array}$ & $1.010^{*}$ & 1.001 & 1.019 & 0.034 \\
\hline
\end{tabular}

Predisposing characteristics

\begin{tabular}{l|l|l|l|l}
\hline Age & $0.989 *$ & 0.983 & 0.996 & 0.001 \\
\hline Female & 1.124 & 0.966 & 1.308 & 0.131 \\
\hline Pre-use of antihypertensives & 1.130 & 0.951 & 1.342 & 0.165 \\
\hline $\begin{array}{l}\text { \% of population self-reporting } \\
\text { white race only }\end{array}$ & $0.992 *$ & 0.987 & 0.997 & 0.003 \\
\hline
\end{tabular}

Enabling resour ces

Living in rural area

Living in super rural area $\dagger$

Household median income

(thousands)

Treatment for depression

Initiated with ACEIs

Unique medications in

prior 6 months (n)

Mail-order service

Doctor visits July 1, 2003 -

December 31, 2004 (n)

Yearly out of pocket maximum

Need factors

Diagnosis of myocardial

infarction

Diagnosis of congestive heart

failure

Diagnosis of cerebrovascular

disease

Diagnosis of essential

hypertension

Diagnosis of diabetes

Diagnosis of dyslipidemia

* Denotes statistically significant, $P<0.05$.

$L R x^{2}(20)=62.40, P$ value $<0.001, A C E I=$ angiotensin-converting enzyme inhibitor $\uparrow$ Super rural is defined as a rural area determined by the Secretary of Housing and Urban Development to be in the lowest 25 th percentile of all rural populations arrayed by population density. ${ }^{49}$

studies are not comparable to the present study because the subjects were current users and because the effect of a fixed benefit design change was being tested. In our crosssectional study, members were newly initiating therapy and had variable per 30 day cost-share amounts ranging from $\$ 0$ to $\$ 128$ 

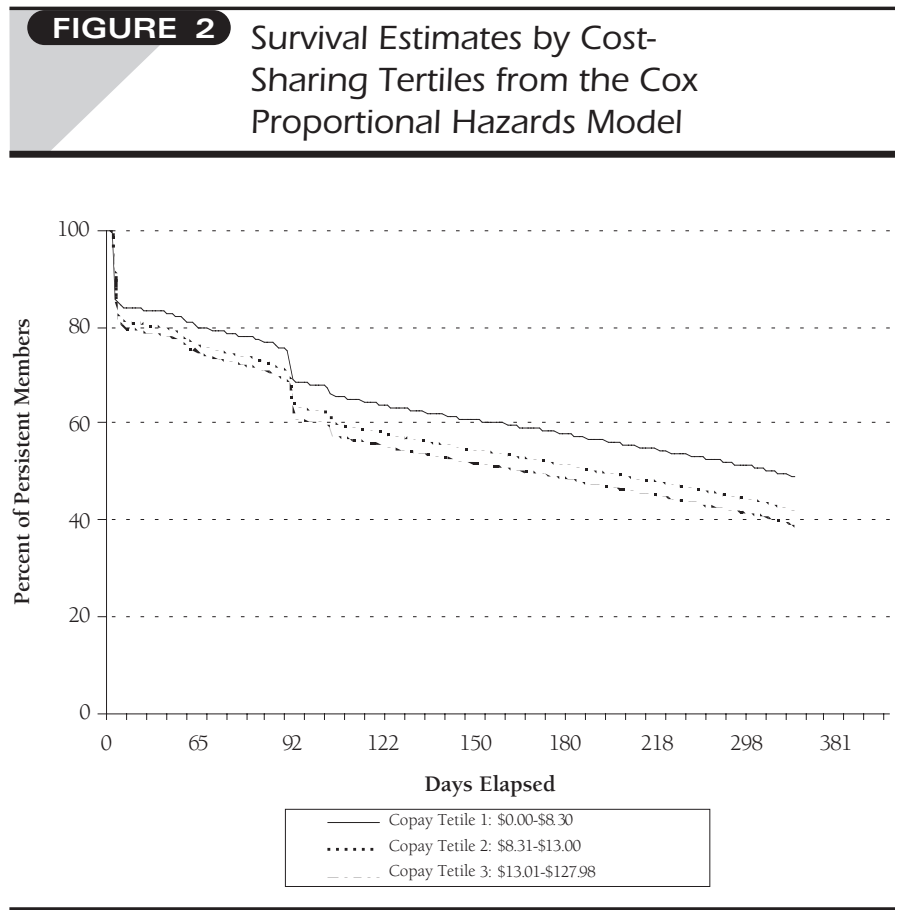

allowing us to quantify the associated relationship between cost share and persistence.

The results of this study are comparable to the findings of other persistence studies employing a cross-sectional study design. Among a combination of members currently utilizing and newly initiating statin therapy, Ellis et al. showed that higher member cost-sharing amounts were associated with large decreases in statin persistence rates. ${ }^{25}$ As compared with members who had a copayment of less than $\$ 10$, members who paid at least $\$ 10$ but less than $\$ 20$ and those who paid $\$ 20$ or greater had $30 \%$ and $211 \%$ greater odds of being nonpersistent (cumulative multiple refill interval gap $[C M G]>20 \%$ ), respectively. A $30 \%$ greater odds of being nonpersistent when comparing a cost-sharing of $\$ 10$ per 30 days supply to $\$ 20$ is similar to the finding in this study of a $31.9 \%$ increase in the odds of being nonpersistent for a mean $\$ 12$ versus $\$ 22$ cost-sharing per 30 days supply. Taira et al. demonstrated that compliance with antihypertensive medications was significantly lower in higher than in lower copayment tiers. ${ }^{27}$ As compared with members who used generics with a copayment of $\$ 5$, members who used preferred brand-name drugs with a copayment of a $\$ 20$ and those who used non-preferred brand-name drugs with a copayment of $\$ 20$ to $\$ 165$ had $24 \%$ and $52 \%$ less odds of being compliant, respectively. Thiebaud et al. found that higher cost-sharing was associated with lower statin utilization. ${ }^{49}$ They reported that a $\$ 1$ increase in brand drug and generic copay was associated with a $0.9 \%$ and $1.6 \%$ decrease in month- ly days supply of brand drug and generics, respectively. These findings are similar to our finding that a $\$ 1$ increase in cost-sharing was associated with a $1.9 \%$ increase in total gap.

We found that age, percentage of population self-reporting white only race in the patient's area of residence, and use of mailorder service were statistically significant predictors of total gap, being nonpersistent, and time to a gap of $>30$ days in the 3 models. Some empirical studies have shown that age and race were significant predictors of medication persistence. ${ }^{31,36,38,40-41}$ Benner et al., for example, reported that members of black and other nonwhite races were less persistent with statin therapy. ${ }^{41}$ Although we also found a significant association between persistence and race, this finding should be interpreted cautiously. Because claims data do not include race at the individual level, we measured race at an aggregate level (i.e., percentage of population in the patient's Zip Code area selfreporting white as their only racial group).

In addition, results of this study suggest that members who fill prescriptions by mail-order pharmacies have greater persistence rates. However, the impact of mail-order service may be artificial because the calculation of persistence in this study was based on days supply recorded in pharmacy claims. Mail-order pharmacies have larger days supply than community pharmacies. Within a fixed observation period, members who receive medications from mail-order pharmacies will have fewer refills than those who use community pharmacies and therefore the former group will be less likely to have a gap. We believe the impact of mail-order claims on our results is minimal because only $8.3 \%$ of all the claims and $18.0 \%$ of total days supply during the first 6 months of treatment are mail-order. In addition, mail-order was adjusted for in all 3 models. In order to remove the possibility of the impact of mail-order service on the outcome, the 3 models were rerun with restriction to members with community pharmacy claims only. The impact of cost-share on persistence did not change in all the 3 models (data not shown).

We also found that having an out-of-pocket annual maximum on prescription drug spending and having diagnoses of dyslipidemia and myocardial infarction were associated with a lower total gap in the Tobit model. We did not find similar relationships with the odds of being nonpersistent and the risk of having an unallowable gap in the logistic regression and Cox proportional hazards models. These differences in independent predictors between the Tobit model compared with the logistic regression and the Cox proportional hazards model may be due to the fact that the Tobit model allows for persistence (total gap) as a continuous variable, while the logistic regression requires persistence to be dichotomized (persistent vs. nonpersistent) and persistence is measured as time to an unallowable gap or duration in the Cox proportional hazards model.

We adapted Andersen's behavioral model of health services use as a conceptual framework to select important variables 
to control in examining the relationship between cost-sharing and medication persistence. The results suggested that Andersen's model is valid as a guidance to select predictor variables for examining medication persistence. In this study, for example, the logistic model explained approximately $9 \%$ of the variance in medication refill persistence (pseudo- $R^{2}=0.09$ ). Our $R^{2}$ value is improved over that of Cole et al., who reported an $R^{2}$ value of $0.06 .^{23}$

\section{Limitations}

The primary limitation of this study is its cross-sectional design, which is vulnerable to the effects of confounding factors. The $9 \%$ pseudo- $R^{2}$ value in our logistic regression model suggests that a substantial portion of the variance in medication refill persistence was not explained by our model, a problem typical of cross-sectional studies of this topic. Previous observational work has indicated that patients initiating treatments with generic drugs (lower cost-share) have somewhat higher adherence rates than do those initiating with brand drugs (higher cost-share); however, a randomized study is necessary for a rigorous test of the effects of initial cost-share on early medication persistence. ${ }^{26}$ The need for further research is highlighted by recent quasi-experimental (pre-post with comparison) study of diabetic supply utilization before and after the implementation of a policy mandating provision of free diabetes supplies including glucose testing strips to patients with diabetes mellitus. Crosssectional analysis documented an association between higher cost-sharing levels for the testing strips and lower compliance with blood glucose testing guidelines prior to implementation. Yet implementation of the free test strip policy was not associated with a change in adherence to testing guidelines, even among lower-income patients and those paying the highest cost-share prior to the policy change..$^{50}$

Second, medication persistence is defined narrowly in the present study to include single-agent ACEI or ARB. While switching between single-agent ARB or ACEI was permitted, drug therapy was considered terminated if the patient switched to an ACEI or ARB in combination with hydrochlorothiazide (HCTZ) or to an antihypertensive in a different class such as a calcium channel blocker, diuretic, or a beta blocker. Third, our measurements of refill persistence depended on days supply recorded in pharmacy claims data. ACEI or ARB refill persistence may be underestimated in this study because other sources for acquiring prescription medications, such as free samples from physicians, could not be identified in claims data.

Fourth, the subjects of this study may have self-selected the Midwest commercial insurer as their health plan. Although pharmacy benefits are usually the same within one health plan and similar across different health plans for the same employer, this study may have been subject to a selection bias. However, to our knowledge, the pharmacy benefits were the same regardless of the health benefits selected by the member within one employer.
Fifth, the members of this study were mostly younger than 65 years. Therefore, the results of this study may not be generalizable to older adults.

Sixth, our results are limited to members newly initiating angiotensin system-blocking agents and may not be generalizable to established medication users or other drug classes. Seventh, we attributed interruption of refills to members' nonpersistence behavior. However, these interruption decisions may have been made by physicians as a result of ineffectiveness or side effects. Nonetheless, these decisions should affect members with lower and higher levels of cost-sharing equally. Eighth, some control variables, including income and race, were measured on an aggregate Zip Code level instead of on the individual level. Ninth, the duration of this study may be of concern to some readers. We followed the members for a minimum of 6 months and up to 1 year. The relatively short study duration was based on previous research, which has shown that the largest decrease in antihypertensive persistence occurs between 3 and 6 months after initiating therapy. ${ }^{40,51}$

Finally, in 2004, benazepril (Lotensin) and quinapril (Accupril) became generically available in February and December, respectively, resulting in lower member cost-sharing (i.e., generic cost-sharing). These 2 drugs were used by less than $5 \%$ of ACEI users and exclusion of these members in sensitivity analyses did not influence the results.

\section{Policy Implication}

This study has several implications for policy making. Payers have experimented with lowering medication cost-sharing for chronic diseases such as hypertension, hyperlipidemia, and diabetes, where medication has been shown to prevent morbidity and mortality. ${ }^{52,53}$ Although zero-dollar member cost-sharing for selected chronic conditions has been proposed, a starting point may be a zero-dollar or near zero-dollar cost-sharing for generic drugs, which has been adopted by some employers. ${ }^{54} \mathrm{~A}$ zero-dollar generic cost-share will potentially reduce cost to all beneficiaries and improve persistence; however, to our knowledge, currently there are no well-controlled studies indicating that zero-dollar cost-sharing improves medication adherence. Knowing a relationship exists between how much an individual pays for medication and how long he or she will remain persistent is the first step to improving pharmacy benefits designs. We echo the statements made by others: "The challenge remains to make individuals more sensitive to the cost of treatment without encouraging them to forgo cost effective care." ${ }^{.2}$

\section{CONCLUSION}

This study adds to the literature through further quantifying the association between the amount of member prescription cost-share and medication refill persistence. Among members newly initiating an ACEI or ARB, a $\$ 10$ greater cost-share was associated with $31.9 \%$ greater odds of being nonpersistent at 


\section{Relationship of the Magnitude of Member Cost-Share and Medication Persistence with Newly Initiated Renin Angiotensin System Blockers}

6 months after initiating therapy. To our knowledge, this is the first study to quantify the association between the dollar amount of member cost-share and total gap in therapy among members newly initiating ACEI or ARB therapy. For every $\$ 10$ greater cost-share, we found an associated $18.9 \%$ increase in total medication gap during the first 6 months of follow-up. Further research is needed to validate these findings and to investigate this relationship among other antihypertensive drug classes and other chronic medications. Insurers should consider the impact that cost-share has on angiotensin system-blocking medication persistence when designing their pharmacy benefit offerings.

\section{Authors}

At the time the work was completed, DONGMU ZHANG was a PhD candidate, University of Minnesota, Minneapolis, MN. STEPHEN W. SCHONDELMEYER, PhD, and JON C. SCHOMMER, PhD, are professors of Social and Administrative Pharmacy, and BRYAN E. DOWD, PhD, is professor of Health Policy and Management, University of Minnesota, Minneapolis, MN; ANGELINE M. CARLSON, PhD, is president, Data Intelligence Consultants LLC, Eden Prairie, MN; PATRICK P. GLEASON, PharmD, is Director of Medical and Pharmacy Integration Services, Prime Therapeutics LLC, Eagan, MN; ALAN H. HEATON, PharmD, is Director of Pharmacy, BlueCross BlueShield of Minnesota, Eagan, MN.

CORRESPONDING AUTHOR:

Dongmu Zhang, PhD, Statistical Services, IMS Health, 960A Harvest Drive, Blue Bell, PA 19422. Tel.610-832-5808; Fax: 610-832-5850;

E-mail:DZhang@us.imshealth.com

\section{ACKNOWLEDGMENTS}

The authors thank Carol Walters, MBA, Senior Consulting Analyst, Prime Therapeutics LLC, Eagan, MN, for her technical assistance in extracting the data for analysis.

\section{DISCLOSURES}

An abstract of this manuscript was the basis of a podium presentation at the 12th Annual International Meeting of the International Society of Pharmacoeconomics and Outcomes Research (ISPOR) in May 2007. The authors disclose no bias or conflict of interest relating to this article.

Dongmu Zhang served as principal author of the study. Study concept and design were contributed by Zhang and Angeline M. Carlson and Stephen W. Schondelmeyer with input from Patrick P. Gleason, Jon C. Schommer, and Bryan E. Dowd. Data collection was the work of Zhang with assistance from Schommer, Carlson, Gleason, Schondelmeyer, and Alan H. Heaton; data interpretation was primarily the work of Zhange with input from Dowd, Carlson, Gleason, Schondelmeyer, and Schommer. Writing of the manuscript and its revision was primarily the work of Zhang with input from Gleason, Heaton, and Carlson.

\section{REFERENCES}

1. Centers for Medicare and Medicaid Services (CMS). NHE Web Tables. Available at http://www.cms.hhs.gov/NationalHealthExpendData/downloads/ tables.pdf. Accessed March 19, 2007.

2. Crown WH, Berndt ER, Baser O, et al. Benefit plan design and prescription drug utilization among asthmatics: Do patient copayments matter? Front Health Policy Res. 2004;7:95-127.
3. Kaiser Family Foundation and Health Research and Educational Trust. Employer Health Benefits - 2006 Annual Survey. Available at http://www.kff. org/insurance/7527/index.cfm. Accessed March 19, 2007.

4. Goldman DP, Joyce GF, Zheng Y. Prescription drug cost sharing association with medication and medical utilization and spending and health. JAMA. 2007;298:61-69.

5. Joyce GF, Escarce JJ, Solomon MD, et al. Employer drug benefit plans and spending on prescription drugs. JAMA. 2002;288(14):1733-39.

6. Gibson TB, Mark TL, Axelsen K, et al. Impact of statin copayments on adherence and medical care utilization and expenditures. Am J Manag Care. December 2006;12(special issue):SP11-19.

7. Gibson TB, Mark TL, McGuigan KA, et al. The effects of prescription drug copayments on statin adherence. Am J Manag Care. 2006;12 (9):509-17.

8. Huskamp HA, Deverka PA, Epstein AM, et al. The effect of incentive-based formularies on prescription-drug utilization and spending. N Engl J Med. 2003:349:2224-32.

9. Goldman DP, Joyce GF, Escarce JJ, et al. Pharmacy benefits and the use of drugs by the chronically ill. JAMA. 2004;291(19):2344-50.

10. Huskamp HA, Deverka PA, Epstein AM, et al. Impact of 3-tier formularies on drug treatment of attention-deficit/hyperactivity disorder in children. Arch Gen Psychiatry. 2005;62(4):435-41.

11. Roblin DW, Platt R, Goodman MJ, et al. Effect of increased cost sharing on oral hypoglycemic use in five managed care organizations: How much is too much? Med Care. 2005:43(10):951-59.

12. Briesacher B, Kamal-Bahl S, Hochberg M, et al. Three-tiered-copayment drug coverage and use of nonsteroidal anti-inflammatory drugs. Arch Intern Med. 2004;164(15):1679-84.

13. Kamal-Bahl S, Briesacher B. How do incentive-based formularies influence drug selection and spending for hypertension? Health Aff (Millwood). 2004;23(1):227-36

14. Nair KV, Wolfe P, Valuck RJ, et al. Effects of a 3-tier pharmacy benefit design on the prescription purchasing behavior of individuals with chronic disease. J Manag Care Pharm. 2003;9(2):123-33. Available at: http://www.amcp. org/data/jmcp/Research-123-133.pdf.

15. Rector TS, Finch MD, Danzon PM, et al. Effect of tiered prescription copayments on the use of preferred brand medications. Med Care. 2003:41(3):398406.

16. Thomas CP, Wallack SS, Lee $S$, et al. Impact of health plan design and management on retirees' prescription drug use and spending, 2001. Health Aff (Millwood). July-December 2002(suppl Web exclusives):W408-19.

17. Landsman PB, Yu W, Liu X, et al. Impact of 3-tier pharmacy benefit design and increased consumer cost sharing on drug utilization. Am J Manag Care. 2005;11(10):621-28.

18. Hillman AL, Pauly MV, Escarce JJ, et al. Financial incentives and drug spending in managed care. Health Aff (Millwood). 1999;18(2):189-200.

19. Berndt ER, Frank RG, McGuire TG. Alternative insurance arrangements and the treatment of depression: What are the facts? Am J Manag Care. $1997 ; 3(2): 243-50$

20. Motheral BR, Henderson R. The effect of a copay increase on pharmaceutical utilization, expenditures, and treatment continuation. Am J Manag Care. 1999;5(11):1383-94.

21. Motheral BR, Fairman KA. Effect of a 3-tier copay on pharmaceutical and other medical utilization. Med Care. 2001;39:1293-304.

22. Fairman KA, Motheral BR, Henderson RR. Retrospective long-term followup study of the effect of a three-tier prescription drug copayment system on pharmaceutical and other medical utilization and costs. Clin Ther 2003;25(12):3147-61

23. Cole JA, Norman H, Weatherby LB, et al. Drug copayment and adher- 


\section{Relationship of the Magnitude of Member Cost-Share and Medication Persistence with Newly Initiated Renin Angiotensin System Blockers}

ence in chronic heart failure: Effect on cost and outcomes. Pharmacother 2006;26(8):1157-64

24. Pilote L, Beck C, Richard H, et al. The effects of cost-sharing on essential drug prescriptions, utilization of medical care and outcomes after acute myocardial infarction in elderly patients. Can Med Assoc J. 2002;167(3):246-52

25. Ellis JJ, Erickson SR, Stevenson JG, et al. Suboptimal statin adherence and discontinuation in primary and secondary prevention populations. J Gen Intern Med. 2004;19:638-45.

26. Shrank WH, Hoang T, Ettner SL, et al. The implications of choice: Prescribing generic or preferred pharmaceuticals improves medication adherence for chronic conditions. Arch Intern Med. 2006;166:332-37.

27. Taira DA, Wong KS, Frech-Tamas F, et al. Copayment level and compliance with antihypertensive medication: Analysis and policy implications for managed care. Am J Manag Care. 2006;12:678-83.

28. Caetano PA, Lam JMC, Morgan SG. Toward a standard definition and measurement of persistence with drug therapy: Examples from research on statin and antihypertensive utilization. Clin Ther. 2006;28:1411-24.

29. Sikka R, Xia F, Aubert RE. Estimating medication persistency using administrative claims data. Am J Manag Care. 2005;11(7):449-57.

30. Joint National Committee on Prevention, Detection, Evaluation, and Treatment of High Blood Pressure. The seventh report of the Joint National Committee on Prevention, Detection, Evaluation, and Treatment of High Blood Pressure. Available at http://www.nhlbi.nih.gov/guidelines/hypertension/ jnc7full.pdf. Accessed Aug 30, 2007.

31. Marentette MA, Gerth WC, Billings, DK, et al. Antihypertensive persistence and drug class. Can J Cardiol. 2002;18(6):649-56.

32. Bloom BS. Continuation of initial antihypertensive medication after 1 year of therapy. Clin Ther. 1998;20(4):671-81.

33. Caro JJ, Speckman JL, Salas M, et al. Effect of initial drug choice on persistence with antihypertensive therapy: The importance of actual practice data. Can Med Assoc J. 1999;160(1):41-46.

34. Darbishire PL, Shepler B, Sutton JM. Differences among angiotensin II receptor blockers. U.S. Pharmacist. 2004;10:HS19-HS25.

35. Agency for Health Research and Quality. Comparative effectiveness of angiotensin-converting enzyme inhibitors (ACEIs) and angiotensin II receptor antagonists (ARBs) for treating hypertension. Available at: http://effectivehealthcare.ahrq.gov/repFiles/ACEIs_v_ARBs_Draft_Report.pdf Accessed March 19, 2007

36. Perreault S, Lamarre D, Blais L, et al. Persistence with treatment in newly treated middle-aged patients with essential hypertension. Ann Pharmacother. 2005;39(9):1401-08

37. Andersen RM. Revisiting the behavioral model and access to medical care: Does it matter? J Health Soc Behav. 1995;36(3):1-10.

38. Caro JJ, Salas M, Speckman JL, et al. Persistence with treatment for hypertension in actual practice. Can Med Assoc J. 1999;160(1):31-37.
39. Grant RW, O'Leary KM, Weilburg JB, et al. Impact of concurrent medication use on statin adherence and refill persistence. Arch Intern Med. 2004; 164:2343-48

40. Wogen J, Kreilick CA, Livornese RC, et al. Patient adherence with amlodipine, lisinopril, or valsartan therapy in a usual-care setting. J Manag Care Pharm. 2003;9(5):424-29. Available at: http://www.amcp.org/data/jmcp/Research-424429.pdf.

41. Benner JS, Glynn RJ, Mogun H, et al. Long-term persistence in the use of statin therapy in elderly patients. JAMA. 2002;288:455-61.

42. Xu KT, Smith SR, Borders TF. Access to prescription drugs among noninstitutionalized elderly people in west Texas. Am J Health Syst Pharm. 2003;60(7):675-82

43. Farley JF, Cline RR, Hansen RA. Resorptive drug use among communitydwelling women in Minnesota. Am J Health Syst Pharm. 2004;61(15):1577-85.

44. Devine JW, Farley JF, Hadsall RS. Patterns and predictors of prescription medication use in the management of headache: Findings from the 2000 Medical Expenditure Panel Survey. Headache. 2005;45:1171-80.

45. US Census Bureau. Summary file 3 (SF 3). Available at http://www.census. gov/Press-Release/www/2002/sumfile3.html. Accessed August 2, 2005.

46. Wisconsin Physicians Service. Ambulance zip code files. Available at http:// www.wpsic.com/medicare/provider/amb_zips.shtml. Accessed August 2, 2005.

47. Rural Health Resource Center. An alternative approach to defining rural for the purpose of providing emergency medical services (EMS). Available at http://tasc. ruralhealth.hrsa.gov/documents/Ems_Definition_Of_Rural_Complete.pdf. September 7, 2007

48. Center for Medicare and Medicaid Services (CMS). Medicare boosts payments for ambulance services. Available at http://www.cms.hhs. gov/apps/media/press/release.asp?Counter=1100. Accessed September 7, 2007.

49. Thiebaud P, Pate BV, Nichol MB. The demand for statin: The effect of copay on utilization and compliance. Health Econ. 2007 Jun 22; [Epub ahead of print].

50. Karter AJ, Parker MM, Moffet HH, et al. Effect of Cost-sharing Changes on Self-monitoring of Blood Glucose. Am J Manage Care. 2007;13:408-16.

51. Benson S, Vance-Bryan K, Raddatz J. Time to patient discontinuation of antihypertensive drugs in different classes. Am J Health Syst Pharm. 2000;57(1):51-54

52. Goldman DP, Joyce GF, Karaca-Mandic P. Varying Pharmacy Benefits with Clinical Status: The Case of Cholesterol-lowering Therapy. Am J Manag Care. 2006;12(1):21-28

53. College to pay for diabetes medicine. USA Today. April 24, 2006:1B

54. Fuhrmans V. Employers, insurers push generics harder: As many blockbusters go off-patent some health plans drop copays for copycats. Wall Street J October 31, 2006:Dl. 